Comparative Study for Usage of Coconut Water from

Ripe and Unripe Coconut as a Substituent for Oral

\author{
Rehydration Fluid
}

By

Nilamuni Hiranya Prabhashini de Silva

Thesis submitted to the University of Sri Jayewardenepura for the award of the Master of Science in Food Science and Technology on $23^{\text {rd }}$ July 2015. 


\section{DECLARATION}

"The work described in this thesis was carried out by me under the supervision Dr. Indira Wickramasinghe, Senior Lecturer, Department of Food Science \& Technology, Faculty of Applied Science of the University of Sri Jayewardenepura, Dr. Chandani Udawatte, Senior Lecturer, College of Chemical Sciences, Institute of Chemistry Ceylon and Mr. S. C. Dilanka Fernando, Visiting Lecturer, Management \& Science Institute, and a report on this has not been submitted in whole or in part to any university or any other institution for another degree/diploma."

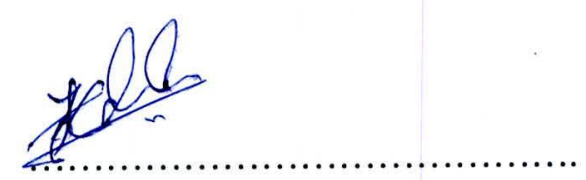

Nilamuni Hiranya Prabhashini de Silva

Date: 23.07 .2015 


\section{DECLARATION}

We certify that the above statement made by the candidate is true and that this thesis is suitable for submission to the University for the purpose of evaluation

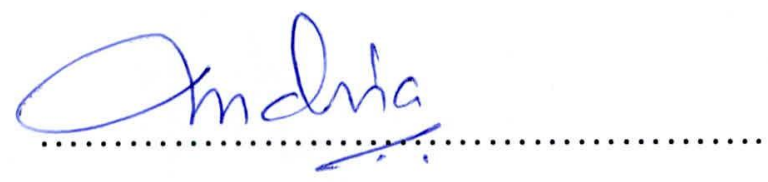

Dr. Indira Wickramasinghe

Senior Lecturer,

Department of Food Science \& Technology,

Faculty of Applied Sciences,

University of Sri Jayewardenepura

23-07-2015

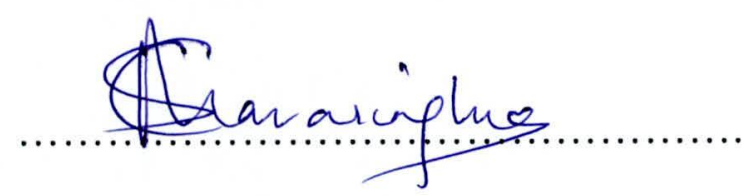

Dr. Chandani Udawatte

Senior Lecturer,

College of Chemical Sciences,

Institute of Chemistry Ceylon

23-07-2015

Mr. S. C. Dilanka Fernando

Visiting Lecturer,

Management \& Science Institute

23-07-2015 


\section{TABLE OF CONTENTS}

\section{Page}

List of Tables

List of figures

\section{CHAPTER 1 : INTRODUCTION}

CHAPTER 2 : LITERATURE REVIEW

2.1 Coconut (Cocos nucifera)

2.2 Coconut maturity

2.3 Coconut water

2.4 Dehydration $-1-5$

2.5 Rehydration -

2.6 Oral rehydration Salts (ORS)

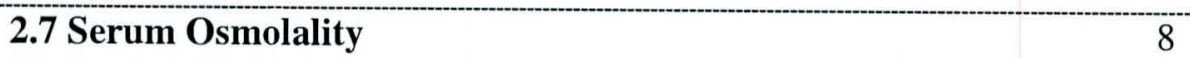

2.8 GOD/POD Method of Glucose analysis $\quad 10$

CHAPTER 3 : MATERIALS AND METHODOLOGY -11

3.1 Materials

3.2 Chemicals and reagents

3.3 Methods $-1-1$

3.3.1 Collection of coconut water

3.3.2 Determination of the mineral element content 13 
3.3.4 Determination of the chloride content

3.3.5 Determination of the osmolality

3.3.6 Determination of the content of antioxidants

3.4 Statistical data analysis

\section{CHAPTER 4 : RESULTS AND DISCUSSION}

4.1 Analysis of Sodium content

4.2 Analysis of Potassium content

4.3 Analysis of Magnesium content

4.4 Analysis of Calcium content

4.5 Analysis of Glucose content

4.6 Analysis of Chloride content

4.7 Analysis of Osmolality of the samples

4.8 Analysis of the content of Antioxidants

CHAPTER 5 : CONCLUSION 


\section{List of tables}

Table. 1 : Biological taxonomy of Coconut palm grown in Sri Lanka

Table. 2: Composite results of the coconut samples analyzed

Table. 3 : ANOVA P values for the variation of sodium content in the

three maturity states among the four districts

Table. 4 : ANOVA P values for the variation of potassium content in

the three maturity states among the four districts

Table. 5 : ANOVA P values for the variation of magnesium content in

the three maturity states among the four districts

Table. 6 : ANOVA P values for the variation of calcium content in the

three maturity states among the four districts

Table. 7 : ANOVA P values for the variation of glucose content in the three maturity states among the four districts

Table. 8 : ANOVA P values for the variation of chloride content in the three maturity states among the four districts

Table. 9 : ANOVA P values for the variation of osmolality in the three maturity states among the four districts

Table. 10 : ANOVA P values for the variation of $L$ Ascorbic acid equivalent concentration of percentage inhibition in the three maturity states among the four districts 


\section{List of Figures}

\section{Page}

Figure 1: Cross section of $C$. nucifera

Figure. 2 : Composition requirements for a new Oral Rehydration

Solution according to the WHO

Figure. 3 : Variation of the sodium content of the coconut water

samples with the maturity state between each area of sample collection

Figure. 4: Variation of the potassium content of the coconut water

samples with the maturity state between each area of sample collection

Figure. 5: Variation of the magnesium content of the coconut water

samples with the maturity state between each area of sample collection

Figure. 6: Variation of the calcium content of the coconut water

samples with the maturity state between each area of sample collection

Figure. 7 : Variation of the glucose content of the coconut water

samples with the maturity state between each area of sample collection

Figure. 8: Variation of the chloride content of the coconut water

samples with the maturity state between each area of sample collection

Figure. 9: Variation of the osmolality of the coconut samples with the

maturity state between each area of sample collection

Figure. 10 : Variation of L Ascorbic acid equivalent concentration of percentage inhibition of the coconut water samples with the maturity

state between each area of sample collection with maturity state 


\section{ACKNOWLEDGEMENTS}

This thesis owes its existence to the help, support and inspiration of several people. Firstly, I would like to express my sincere appreciation and gratitude to my supervisor, Dr. Indira Wickramasinghe, Senior Lecturer, Department of Food Science and Technology, Faculty of Applied Sciences, University of Sri Jayewardenepura for her guidance during my research. Her support and inspiring suggestions have been precious for the development of this thesis content.

I am also indebted to my external supervisor, Dr. Chandani Udawatte, Senior Lecturer, College of Chemical Sciences, Institute of Chemistry, Ceylon who has always been a constant source of encouragement and enthusiasm guiding me not only during this project but throughout my academic life.

And I would like to express my special appreciation and heartfelt thanks to my external co-supervisor Mr. Chamira Dilanka Fernando, who have been a tremendous mentor, for encouraging my research, guiding me in the entire period with great understanding and for allowing me to grow as a researcher.

I wish to express my sincere thanks to all the staff members of the Institute of Chemistry, Ceylon for providing me chemicals, consumables and instrumental facilities for my research. A special thank goes to all the lecturer and the staff members of Department of Food Science and Technology, Faculty of Applied Sciences, University of Sri Jayewardenepura for all the support provided throughout the two years as a postgraduate student. And also my gratitude goes to the staff members of Physiological 
Department, Faculty of Medicine, University of Sri Jayawardenepura for the support they provided during Osmolality analysis.

I am very grateful to my parents, friends and my colleagues who always stood by me and gave the necessary encouragement and support whenever required. 


\title{
Comparative study for usage of coconut water from ripe and unripe coconut as a substituent for oral rehydration fluid
}

\author{
Nilamuni Hiranya Prabhashini de Silva
}

\begin{abstract}
Coconut (Cocos nucifera) is one of the major plantation crops in Sri Lanka which accounts for approximately $12 \%$ of all agricultural produce in Sri Lanka. Our country owns the fourth position of world export of all kernel products and there are various other industries producing coconut related products. Coconut water is a clear liquid found in the interior of the coconut. In a healthy and undamaged coconut, the water is considered to be sterile and in spite of being a nutrient and electrolyte rich fluid, coconut water is considered as a waste by most of the coconut related industries. Acute diarrhoeal diseases are one of the leading causes of mortality in infants and young children in many developing countries. In most cases, death is caused by dehydration. This can be easily prevented by the introduction of an electrolyte rich rehydration fluid. Therefore, the major objective of this research was to analyze the feasibility of using coconut water as a rehydration fluid.

A pilot study was conducted prior to the research project to identify the major areas through which coconut enter in to a randomly selected market. As per the results, four areas from four different districts namely, Padiyagampola (Rathnapura), Galle (Galle), Mathugama (Kaluthara) and Kurunegala (Kurunegala) were selected for sample collection. Three maturity states namely pre-matured (6-7 months after flowering), matured (11-12 months after flowering) and over-matured (13-14 months after
\end{abstract}


flowering) were selected from each area and five coconut water samples were selected randomly from each maturity state. Five rehydration biochemical properties namely glucose content, Sodium content, Potassium content, Chloride content and Osmolality were analyzed for each sample. Glucose content was analyzed by using Glucose oxidase/ Peroxidase colourimetric method. Sodium and Potassium contents were analysed using Flame Atomic Absorption Spectrometry (FAAS), Chloride content was determined using a Choride Ion Selective Electrode (Chloride ISE) and Osmolality of the samples was analysed using an Advanced Micro freezing point depression Osmometer. Results were statistically analyzed using one-way analysis of variance (ANOVA), at 0.05 probability level with MINITAB-15 software package. According to the statistical analysis, there was a significant difference in the biochemical parameters assessed between the maturity states as well as between the different areas. This can be due to the biochemical changes that occur during the development stages of the coconut and on geochemical differences in the soil where the plants were grown.

Each property was compared with the World Health Organization (WHO) standards for the Production of new Oral Rehydration Salts. The Potassium content and the Osmolality of all the samples were higher than the WHO standard levels and all the other properties namely, Glucose content, Sodium content and Chloride content were lower than the WHO standard.

As some additional nutritional factors, Magnesium content, Calcium content and Anti oxidants content were analyzed by using Flame Atomic Absorption Spectrophotometry (FAAS) and DPPH antioxidant colourimetric assay respectively. The samples were resulted to be containing a considerable amounts of $\mathrm{Ca}, \mathrm{Mg}$ and Antioxidants. 


\section{CHAPTER 1}

\section{INTRODUCTION}

Coconut (Cocos nucifera) is one of the major plantation crops in Sri Lanka which accounts for approximately $12 \%$ of all agricultural produce in Sri Lanka. Total land area under cultivation is 395,000 hectares and about 2,500 million nuts are produced per year (Department of Census and Statistics, 2003). Sri Lanka is very popular in world market for Desiccated Coconut and holds the $04^{\text {th }}$ position of world export of all kernel products. Also, there are various other industries producing coconut related products. Coconut water is considered to be one of the major waste products in these industries, (Azam-Ali and Battcock, 1998) despite being a sweet and sterile fluid composed of unique chemicals such as sugars, vitamins, minerals, electrolytes, enzymes and amino acids (Jayalekshmy et al., 1982).

Coconut water is the juice of the endosperm found within the cavity of the coconut, which begin to form around 2 months after the natural opening of the inflorescence (Vigliar et al., 2006). Even though a number of researches have been carried out internationally regarding the rehydration properties of coconut water, there are a small number of studies that have related the composition of coconut water to the stage of maturation of the coconut or with the area where the coconut palms grow. Therefore this research was decided to be carried out in order to analyze the biochemical profile of coconut water from coconut palms planted in four different areas of the country and also in three different maturity stages namely pre- matured, matured and over-matured to assess its' suitability to be used as an Oral Rehydration fluid. 
Acute diarrhoeal diseases are one of the leading causes of mortality in infants and young children in many developing countries. In most cases, death is caused by dehydration. It can be treated simply, effectively, and cheaply in all age-groups and in all but the most severe cases by oral administration of a glucose- containing electrolyte solution (World Health organization, 2005). Since coconut water contains those essential nutrients, it can be used as an oral-rehydration fluid.

\section{Major objective}

To analyze the feasibility of using coconut water as a possible rehydration fluid.

\section{Specific objectives}

To analyze the biochemical profile of coconut water from coconut palms planted in four different areas of the country. 


\section{CHAPTER 2}

\section{LITERATURE REVIEW}

\subsection{Coconut (Cocos nucifera)}

Cocos nucifera, the coconut palm, is a monocot perennial member of the Arecaceae (palm - family), cultivated in tropical areas worldwide mainly in Asia, South America and Africa (Moore and UHL, 1982). The coconut fruit is a fibrous drupe. It consists of a thin hard skin (exocarp), a thicker layer of fibrous husk (mesocarp), the white kernel (endosperm) and a large cavity filled with liquid (Chan and Elvitch, 2006).

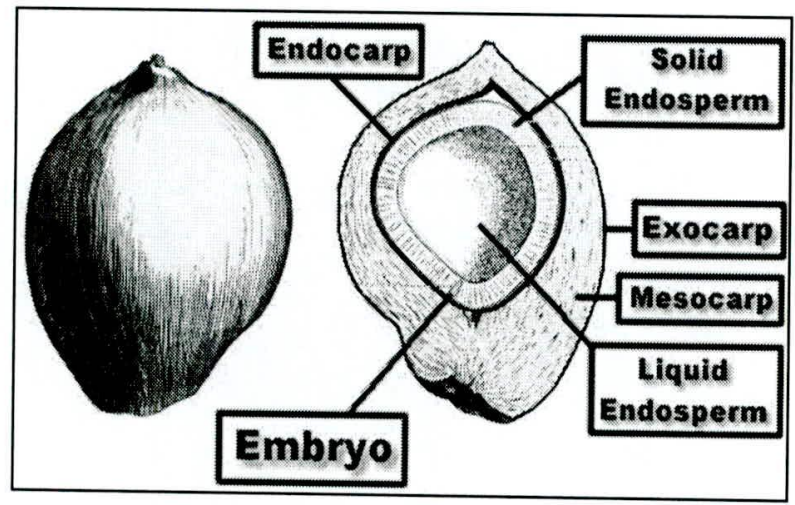

Figure 1. Cross section of $C$. nucifera

Table 1. Biological taxonomy of Coconut palm in Sri Lanka

\begin{tabular}{|l|l|}
\hline Kingdom: & Plantae \\
\hline Order: & Arecales \\
\hline Family: & Arecaceae \\
\hline Subfamily: & Arecoideae \\
\hline Tribe: & Cocoeae \\
\hline Genus: & Cocos \\
\hline Species: & C. nucifera \\
\hline Variety & Typica (Sri Lankan tall) \\
\hline
\end{tabular}




\subsection{Coconut maturity}

The coconut palm starts to bear fruits 3 to 5 years after planting. A normal-bearing, adult palm produces at least one mature ready-to-harvest bunch of coconuts every month (Mathes and Marikkar, 2004). Depending on the variety, the number of nuts per bunch can vary from 5 to 15 . Mature trees continue to produce fruit regularly throughout the year (United States Agency for International Development, 2004).

The coconut fruit takes between 11 to 12 months after flowering to reach complete maturity. (Harries, 2012)

\subsection{Coconut water}

Coconut water is a clear liquid found in the interior of coconut. In a healthy and undamaged coconut, the water is sterile. Its sodium and potassium content makes it an ideal drink for rehydration. The characteristics of the coconut water changes as the nut ages. (Prades, et al., 2012)

The edible part of the coconut fruit consists of the endosperm tissue. Endosperm tissues undergo one of the three main modes of development, ie; nuclear, cellular and helobial modes. The development of coconut endosperm occurs in the nuclear development mode (Cutter et al., 2009). Initially, the endosperm is a liquid containing free nuclei generated by a process, in which the primary endosperm nucleus undergoes several cycles of division without cytokinesis. Cytokinesis then occurs, progressing from the periphery towards the center, thus forming the cellular endosperm layer. At first, the cellular endosperm is translucent and jelly-like, but it later hardens at maturity to 